\title{
Лазерное гетеродинное микрозондирование как метод отображения внутренних неоднородностей оптических материалов
}

\author{
И.Ш. Штейнберг*, П.Е. Твердохлеб, А.Ю. Беликов \\ Институт автоматики и электрометрии СО РАН, \\ 630090, г. Новосибирск, просп. Академика Коптюга, 1 \\ E-mail: steinberg@iae.nsk.su
}

DOI:10.31868/RFL2018.202-203

В данной работе представлен разработанный нами метод гетеродинного микрозондирования, предназначенный для исследования распределения фазовых неоднородностей внутри прозрачных оптических материалов. Метод основан на проведении поточечного 3D сканирования образца оптическим микрозондом и последующего синтеза изображения. Микрозондом является световое распределение в виде бегущей микрорешетки, которая формируется в области пересечения двух сфокусированных пучков в исследуемом образце (см. рис. 1): один из которых опорный - 1, а другой гетеродинный 2. Частота пучка 2 сдвинута относительно частоты опорного пучка на величину $\Delta F=88$ МГц.

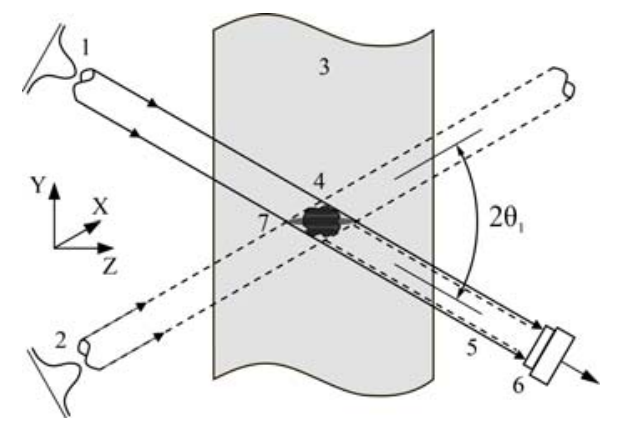

Рис. 1. Схема, поясняющая принцип гетеродинного микрозондирования
Эта интерференционная микрорешетка затем совмещается с микронеоднородностью 4 в объеме лазерной керамики 3. Часть излучения гетеродинного пучка 2, рассеянного на этой микронеоднородности, будет распространяться в направлении фотодетектора 6. В этом же направлении будет распространяться и часть излучения пучка 1 , прошедшая без рассеяния. Взаимодействие этих двух пучков света с разными частотами приводит к возникновению фототока с разностной частотой $\Delta F$ на выходе фотодетектора 6. Было показано,

что величина относительной доли мощности излучения гетеродинной волны, рассеянной на микронеоднородностях пропорциональна квадрату величины гетеродинного фототока. Следует отметить, что детектируется только то рассеянное на микронеоднородности световое поле гетеродинного пучка 5 , которое совпадает по направлению (угловому спектру пространственных гармоник) с прошедшей без рассеяния частью опорного пучка 1 . Кроме того, из рис. 1 видно, что детектирование происходит только в области пересечения пучков 1 и 2, вследствие чего гетеродинный микрозонд обладает высокой пространственной селективностью.

Пространственное разрешение метода определяется размерами микрорешетки сформированной в исследуемом материале в результате пересечения сфокусированных пучков 1 и 2 . При использовании излучения с длиной волны 660 нм, среды с показателем преломления $n=1,5$ и фокусирующего объектива с числовой апертурой 0,6 наименьшие размеры, полученные нами экспериментально, составляли $\Delta x \times \Delta y \times \Delta \mathrm{z}=0,8 \times 1,2 \times 5,2$ мкм $^{3}$ и 
были близкими к дифракционному пределу. Влияние сферической аберрации приводит к ухудшению разрешающей способности. Показано, что в диапазоне микрозондирования по глубины от 10 до 500 мкм поперечный размер (XY) микрозонда увеличивается в 1,5 раза, а продольный (по оси Z) - в 2,13 раза. Такие изменения существенны, и должны учитываться при обработке результатов микрозондирования.

Объектом исследования была выбрана лазерная керамика. Все исследованные образцы имели вид дисков диаметром $10-12$ мм и толщиной $1-2$ мм. Изучение фазовых неоднородностей образцов проводилось путем их микрозондирования. Рассматривались три стратегии исследования:

а) линейное зондирование образца по глубине из произвольных точек поверхности;

б) формирование $2 \mathrm{D}$ сечения (слоя) путем зондирования из $m$ последовательно расположенных по оси $\mathrm{Y}$ (или $\mathrm{X}$ ) точек поверхности с шагом $d_{\mathrm{y}}$ (или $d_{\mathrm{x}}$ ), соизмеримым с размером микрозонда;

в) формирование массива из $n$ 2D сечений, полученных при зондировании из $m \times n$ точек, составляющих площадку размером $m d_{\mathrm{y}} \times n d_{\mathrm{x}}$ на поверхности диска.

Максимальную информацию о пространственном распределении неоднородностей дает сканирование по стратегии (в), в соответствие с которой было проведено исследование ряда образцов. Каждый цикл сканирования состоял из 41 скана по глубине, образующих слой. Расстояние между сканами составляло 1 мкм. Далее с интервалом 2 мкм проводилось формирование 21 слоя. Таким образом, размер области микрозондирования составил $40 \times 40 \times 240$ мкм $^{3}$. На рис. 2 приведены топограмма одного из слоев (2-го), а также 3D изображение исследуемой области. Сканирование в области от 0 до 30 мкм происходит в воздухе, а далее - в керамике.
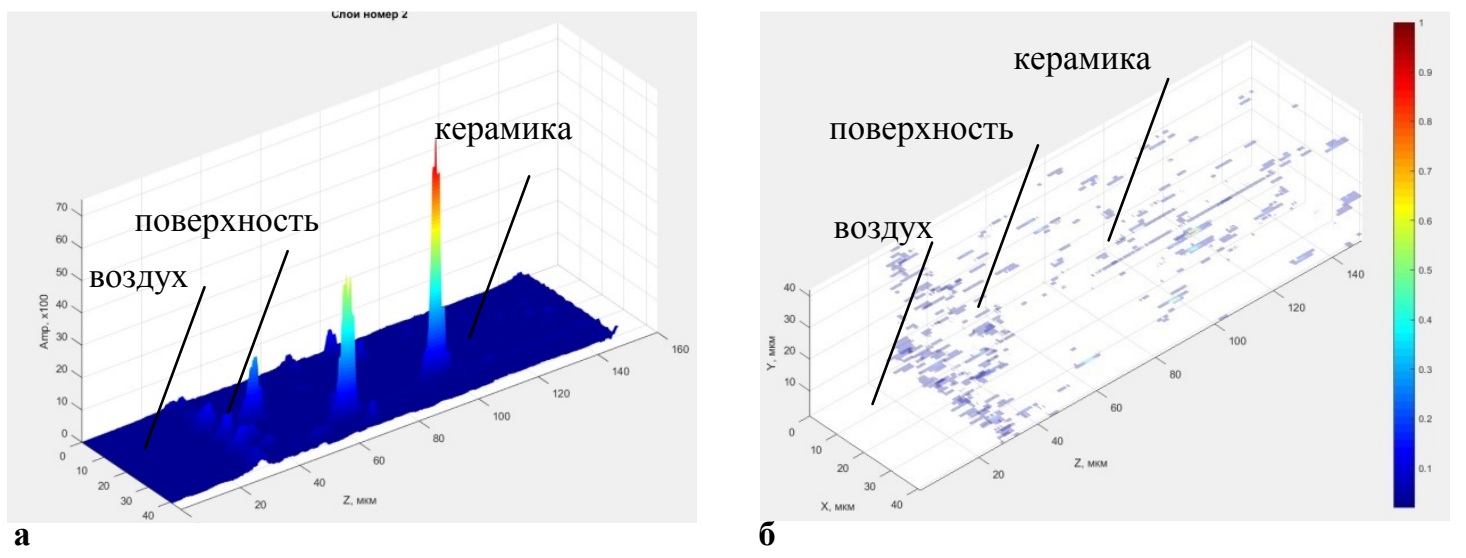

Рис. 2. Распределений фазовых неоднородностей в образце лазерной керамики: a) топограмма 2-го слоя; б) 3D изображение области сканирования

Для проведения количественной оценки качества образцов керамики мы выбрали следующую характеристику - степень неоднородности. Она равна отношению общей площади неоднородностей в анализируемом слое (в процентах) с амплитудой выше некоторой заданной величины (уровень «отсечки») к площади всего слоя. Такая характеристика дает возможность провести сравнение качества разных образцов керамики. Мы полагаем также, что введенная количественная характеристика может коррелировать с порогом генерации лазера, созданного на основе соответствующего образца керамики. 